\title{
Medical student career choice: a qualitative study of fourth- year medical students at Memorial University, Newfoundland
}

\author{
Kiersten Pianosi BSc, Cheri Bethune MD MClSc, Katrina F. Hurley MD MHI
}

Abstract

Background: Specialty career choice is a critical decision for medical students, and research has examined factors influencing particular specialties or assessed it from a demographic perspective. The purpose of this study was to explore and describe influential factors in students' decision-making, irrespective of their particular specialty in a Canadian medical school.

Methods: Study participants were recruited from fourth-year medical classes at the Memorial University of Newfoundland in 2003, 2006, 2007 and 2008. Sixteen focus groups $(n=70)$ were led by a nonfaculty facilitator to uncover factors affecting medical student career choice. The analysis was guided by principles of grounded theory methodology. The focus group transcripts were sequentially coded based on recurring topics and themes that arose in the students' discussions. A set of key themes emerged and representative quotations for each theme were tracked.

Results: Twenty themes were identified from the focus group discussions: 7 major, 3 intermediate and 10 minor themes. The major themes were undergraduate experience, exposure, public perception and recruitment, teacher influence, family/outside influences, residency issues and personal philosophy. Intermediate themes included lifestyle, bad-mouthing/negative perceptions and context. Minor themes included critical incidents/experiences, information gaps, uncertainty, nature of the work, extracurricular programs, timing of decision-making, financial issues, prestige, fit with colleagues and gender issues.

Interpretation: Exposure to specialties and the timing of this exposure appears to be crucial to career choice, as does the context (who, what, when, where) of any particular rotation. Given the influence of personal philosophy, future research examining students' level of self-assessment and self-reflection in their decision-making processes and level of certainty about their selected specialty would be useful.

\begin{abstract}
pecialty career choice is a critical decision for medical students. For most, this decision is an ongoing process throughout their undergraduate schooling. ${ }^{1}$ Although some students know what specialty they want to pursue at the time of entrance, most are influenced by internal and external factors throughout their schooling. ${ }^{2-4}$

Along with other factors, selection of a particular medical specialty can affect the composition of the physician workforce nationwide. ${ }^{5}$ For example, before 2008 the proportion of graduates selecting family medicine in Canada had been declining. ${ }^{6,7}$ Despite a steadily increasing trend of Canadian medical graduates pursuing a career in family medicine since $2008,8,9$ there are still not enough family medicine trainees to satisfy demand and projections for health care workforce planning with our current resources. ${ }^{5}$ Other reports have highlighted graduate underemployment in some specialties. ${ }^{10}$ As we shift toward achieving the right mix and distribution of specialties, the popularity of particular specialties can help postgraduate program directors in framing their training
\end{abstract}

programs to meet the nation's changing health needs, acknowledging our mandate for social accountability. ${ }^{11}$

Factors that influence medical students' career pursuits range from personality and personal attributes, ${ }^{12-14}$ to gender differences, ${ }^{15}$ to issues of prestige and income. ${ }^{16-23}$ Studies in other countries highlight lifestyle issues ${ }^{16}$ and role models ${ }^{24,25}$ as prominent factors influencing medical students. Few studies have addressed career choice on a broad scope. The purpose of this study was to explore and describe what factors are most influential to medical students' career choice, irrespective of their particular specialty in a Canadian medical school.

Competing interests: None declared.

This article has been peer reviewed.

Correspondence to: Katrina Hurley, kfhurley@dal.ca

CMAJ Open 2016. DOI:10.9778/cmajo.20150103 


\section{Methods}

\section{Setting}

This is a qualitative study using focus groups to determine what factors influence medical students' career choice. Medical students at the Memorial University of Newfoundland in the graduating classes of 2003, 2006, 2007 and 2008 were invited to participate in focus groups. Memorial University's medical school program is 4 years long, where the first 2 years are mostly classroom-based and the final 2 years are clinically based. The preclerkship curriculum included exposure to rural practice for 10 days each year. The mandatory clinical rotations are completed in the third year of study, whereas there are elective opportunities from September to November in fourth year. The students have surgical selective opportunities after the Canadian Resident Matching Service (CaRMS) ranking deadline in fourth year.

Study participants were recruited from fourth-year classes in 2003, 2006, 2007 and 2008. Classes were approached as a whole to describe the focus group and identify it as part of the longitudinal survey in which they had participated. Sign-up sheets for each focus group were then posted. Recruitment and participation were timed to occur after the CaRMS results were known (except for the 2003 cohort).

This study was reviewed and approved by the ethics review committee at Memorial University (the Human Investigations Committee) as the second part of a project that also used longitudinal surveys. ${ }^{6}$

\section{Design}

A semistructured guide ${ }^{26}$ was constructed with questions designed to explore the factors that influenced medical students' career choice and how well they felt their schooling prepared them to make this choice (Appendix 1, available at www.cmajopen.ca/content/4/2/E147/suppl/DC1). The questions and prompts were informed by the longitudinal survey of these student cohorts, which tracked students' career path throughout their undergraduate training, including qualitative descriptors. ${ }^{6}$ The focus group questions were piloted with a group of students from a nonparticipating class for clarity.

\section{Data collection}

Focus groups were led by a trained facilitator who was not associated with any aspect of the medical school curriculum. Each focus group included 2-7 (median 4) students. The 2006, 2007 and 2008 focus groups occurred in April of their graduating year; the focus groups for the graduating class of 2003 occurred in December 2002. The facilitator encouraged participants to elaborate on factors that influenced their career choice and decision-making process, whether arising from within the medical school or from external sources. Each focus group discussion lasted 60-90 minutes and was concluded by the facilitator when no new topics emerged. The focus groups were audiorecorded and subsequently transcribed and de-identified.

\section{Analysis}

The qualitative analysis was guided by the principles of grounded theory, which involves the systematic generation of conceptual categories or themes. This inductive methodology builds understanding of a subject from "the ground up" (i.e., from the individuals experiencing the phenomenon). ${ }^{27}$ In this case, those individuals were medical students who were in the final year of their undergraduate program, and the focus groups were used to explore their perspectives and rationale for career choices. Two of us (K.P. and K.F.H.) independently reviewed the transcripts a minimum of 3 times and coded them based on recurring topics and themes that arose in the students' discussions. The first review of the transcripts involved gaining a general understanding and comprehension of each focus group. The second review involved "open coding" (i.e., identifying, naming and categorizing the information found in the transcript data). The third and subsequent reviews involved "axial coding" (i.e., the process of relating categories to each other) to fit the transcript data into basic themes. All themes directly related to the core category of career choice (i.e., "selective coding"). The coding was done systematically by hand in conjunction with spreadsheets to manage categories and track representative quotations, which were used to exemplify each coding theme. Some representative quotations or responses from the transcripts were identified under more than 1 theme (i.e., a single response could generate multiple themes if appropriate). The focus groups were executed as scheduled, and ongoing participation was not based on iterative data analysis. No new themes were identified after focus group 3 in 2007; there were 3 subsequent focus groups after data saturation was reached. We met to ensure consistency and compare relations among the themes, allowing them to explore incongruous ideas. Because participants were de-identified in the transcripts, they were not asked to review the findings of the qualitative analysis.

\section{Results}

Sixteen focus groups with 70 students total were conducted from 2002 to 2008. Analysis of these focus groups revealed 20 recurring themes: 7 major, 3 intermediate and 10 minor themes (Box 1). The themes represent factors that influenced medical students' career choice. Major themes are those that appeared in all focus groups and generated multiple responses/ quotations within each cohort (consistently and frequently) and are represented by representative quotations (Table 1). Intermediate themes are those that appeared either in all of the focus groups with fewer representative quotations or in more than half of the focus groups with multiple representative quotations within a cohort. Minor themes are those that recurred but appeared in less than half of the focus groups with few quotations or in more than half of the focus groups with scant quotations.

\section{Major themes}

\section{Undergraduate experience and exposure}

Most medical students felt that exposure and the undergraduate experience substantially influenced their decisions. More often than not, these 2 influencing factors appeared together 
in the transcripts. Many students felt as though they were not exposed to particular specialties until the end of their undergraduate training, if at all. The curriculum at the university involved didactic teaching on different specialties in first and second year, as well as clinical skills interactions with simulated and real patients. During third year, the students went through their core clerkship rotations (internal medicine, psychiatry, obstetrics, surgery, pediatrics and family medicine); electives took place from September to November of fourth year, with surgery subspecialty selectives occurring after CaRMS interviews. Those students that chose specialties outside of family or internal medicine often commented on the positive role of early exposure in their decision.

\section{Public perception and recruitment}

Recruitment and public perception appeared to be major influencing factors in medical students' career choice. Many students identified incidents where the views of the general public were heavily biased toward or against a particular specialty. Students expressed concern about the perception that the general public ranked family physicians at the bottom of the hierarchy in medicine.

Public perceptions were also mirrored in the media, as some students entered school with skewed ideas of a particular specialty based on television or movies. Recruitment, however, had a greater influencing role toward the end of their program. Overall, students felt enticed to pursue training in certain specialties as the result of positive recruitment efforts by preceptors, mentors and/or specialists.

\section{Teacher, family and partner influences}

Medical students' career choices were heavily influenced by physician/teacher feedback, encouragement and modelling. This reflected what physicians said directly to students during rotations, as well as how much they appeared to enjoy their chosen specialty. These interactions outlined a possible career trajectory within that specialty and played a major role in their career decisions.

People closest to the students, such as family and partners, also had major influences on career choices. They influenced students both by their opinions of specific career paths, where they felt the student would best fit based on their behaviours at home during their clinical rotations and by their attachment to the student. Many students felt like their career choice was not simply their own decision to make when they were in a partnership/relationship.

\section{Personal philosophy}

Many students pursued the specialty about which they felt the most passion. Passion toward a specific specialty positively swayed decisions, regardless of perceived/potential drawbacks or advice from others against a specific specialty.

In addition, the capacity to reflect appeared to have a positive impact on the career choice process for those students who expressed a sense of self-assessment during rotations. Students who were interested in a "competitive program" when entering medical school stayed focused on that specialty throughout their undergraduate schooling; students who reflected on their experience after every specialty exposure then pursued the specialty that was the best fit and about which they were most passionate.

\section{Intermediate themes}

\section{Bad-mouthing/negative perceptions}

Medical students consistently indicated that bad-mouthing of particular specialties occurred in the professional setting, and that it had the ability to affect their career choices. Many students felt as though the bad-mouthing was directed more toward family medicine, although negative perceptions could be voiced about any specialty:

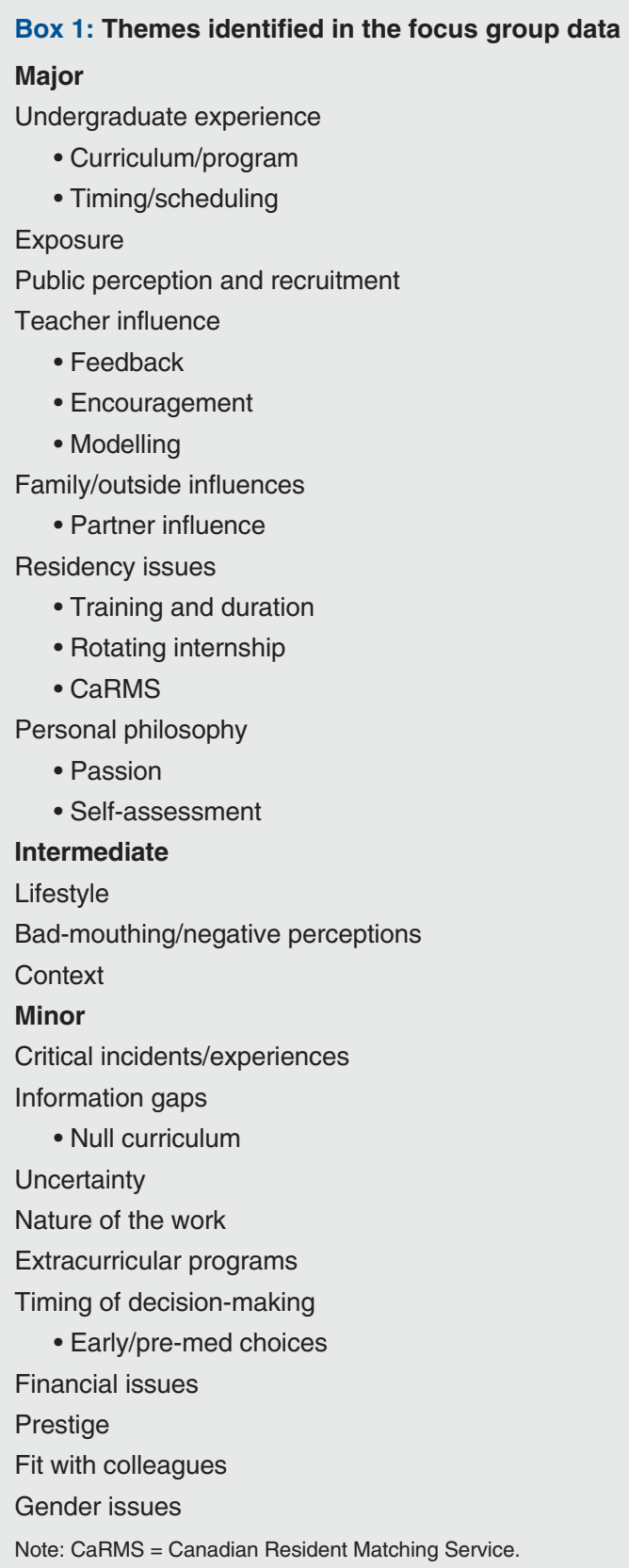




\section{OPEN}

Research

Table 1: Representative quotations from each of the major themes identified

\begin{tabular}{|c|c|}
\hline Major theme & Representative participant quotation \\
\hline $\begin{array}{l}\text { Undergraduate experience } \\
\text { - Curriculum/program } \\
\text { - Timing/scheduling } \\
\text { - Hidden curriculum }\end{array}$ & $\begin{array}{l}\text { "It's like they so devalue the academics of family medicine that we don't even have an exam at the } \\
\text { end of it. It's like there is no material to test you on in family medicine." (2002, FG1) }\end{array}$ \\
\hline Exposure & $\begin{array}{l}\text { "I think the fact that half of our class has switched what they want to do during the clinical years kind } \\
\text { of speaks to the fact that clinical exposure is a strong factor in making that decision." (2002, FG 2) } \\
\text { "I was ranking internal medicine all the way ... but on match day I wanted to do anesthesia, and I } \\
\text { think that's because my last couple weeks of medical school clinical rotations was in anesthesia and I } \\
\text { absolutely loved it and ... I wish I had done this earlier because I would have probably gone for it." } \\
(2002, \text { FG 3) }\end{array}$ \\
\hline Public perception and recruitment & $\begin{array}{l}\text { "You know, it's a deep rooted problem within the public: are you going to be a specialist or just a } \\
\text { family doctor, just a GP." ( } 2006, \mathrm{FG} 3 \text { ) } \\
\text { "After four years of working hard, you kind of want to feel like you're wanted." (2008, FG 1) }\end{array}$ \\
\hline $\begin{array}{l}\text { Teacher influence } \\
\text { - Feedback } \\
\text { - Encouragement } \\
\text { - Modelling/career trajectory }\end{array}$ & $\begin{array}{l}\text { "I think the biggest thing in medical school that influences your decision ... is the feedback you get } \\
\text { from people that you work with.... You look at physicians and say who do I want to be like in } \\
10 \text { years? Do I want to be like him, who enjoys work and having a good time or like that person who's } \\
\text { just cranky and nobody likes." (2002, FG 3) }\end{array}$ \\
\hline $\begin{array}{l}\text { Family/outside influences } \\
\text { - Partner influence }\end{array}$ & $\begin{array}{l}\text { "Coming into med school, with or without a significant other, or meeting a significant other while } \\
\text { you're here. And then you have to take into account where they're going with their life, and if you're } \\
\text { going to have kids, and what your kids are going to do and where they're going to live and those } \\
\text { kinds of things ... that's a big factor." (2007, FG 2) }\end{array}$ \\
\hline $\begin{array}{l}\text { Residency issues } \\
\text { - Training and duration } \\
\text { - Rotating internship } \\
\text { - CaRMS }\end{array}$ & $\begin{array}{l}\text { "One of the things that we used to have [in Canada] is that rotating internship for the year, before we } \\
\text { actually had to make a choice of a specialty. And that year ... you actually had real responsibilities. ... } \\
\text { Everyone said that that year really helped define what they wanted to do with their careers." (2006, } \\
\text { FG 2) } \\
\text { "I think the other problem too is that you're applying to competitive programs. What if you don't get in? } \\
\text { Will you be happy with that? So you're kind of required to pick a couple of things and you know you } \\
\text { pick things that you really don't want to do but you just kind of pick ... it's pretty tough to decide right } \\
\text { now." (2002, FG 5) }\end{array}$ \\
\hline $\begin{array}{l}\text { Personal philosophy } \\
\text { - Passion } \\
\text { - Self-assessment }\end{array}$ & $\begin{array}{l}\text { "Don't worry about the money, and don't worry about how long it'll take to do it. At the end of the day } \\
\text { you need to be happy with what you're doing. And that's what I went with." (2007, FG 2) }\end{array}$ \\
\hline
\end{tabular}

I had a really horrible experience right after my match. I was doing a rotation and I had a surgeon who I had worked with previously. I had done well in the rotation. You know, [he] wanted me to go do surgery and he asked me what I matched. I said family medicine; and in front of everyone, he said — "That's horrible. Why would you do such a thing?" He said, "What a waste." - (2008, Focus Group 3)

I don't know if ... I felt that family medicine got any more trashed than any other area. ... the internal medicine doctors say lots of bad things about the surgeons, everybody trashes everybody else. - (2007, Focus Group 3)

\section{Context}

Context refers not exclusively to what the medical student was doing at the time, but also to where, when and with whom they were doing the rotation. These factors, when combined, provided students with either a positive or negative overall experience. The context of certain rotations or electives was influential in career decisions because students felt it illustrated the overall picture of a given specialty and provided the most memorable experience. For example, all students completed a core internal medicine rotation, but their experiences differed:
Working in different hospitals really kind of helped me make my decision. Because doing internal medicine here it seemed like the staff had no life outside of the hospital, but at other hospitals I felt it was a bit more balanced. ... That kind of made me realize that this hospital is not necessarily the case throughout. - (2006, Focus Group 3)

\section{Minor themes}

\section{Information gaps}

Some medical students felt as though their career choice was influenced by a lack of information provided about specialties and the residency match. This lack of information can be classified as the "null curriculum." Of note, what is not talked about is as important as what is included. ${ }^{28}$ Despite being exposed to a particular specialty, these students found it challenging to obtain information on practical aspects of a career in that area.

Even simple information of what the daily lives of different specialties are like and what they make and how many hours they work and so on, not only is it not presented to us but there was an instance in our first couple of years when that sort of information was sought by people ... and we were specifically told it was information we shouldn't want to know about. — (2007, Focus Group 3) 


\section{Timing of decision-making}

Some medical students started their schooling with an idea of what specialty area they wanted to pursue or made decisions quite early on. Making early or pre-medical school career choices narrowed their options substantially and made their elective choices more targeted. Some medical students believed this type of decision-making process was beneficial and others believed it to be disadvantageous.

I had a lot of trouble because ... I came into medical school with an open mind, which was a bad decision. But I thought that I could do that, and I did have some inkling that you had to, needed to, decide early. — (2008, Focus Group 2)

Some people come in because they want to do something very competitive and then they're focused on that the entire way through, which you have to be, if you want to do something very competitive. And so you kind of have to have tunnel vision the whole time. - (2002, Focus Group 4)

\section{Interpretation}

This study yielded 20 recurring influences over medical student career choice, with 7 themes dominating the data. In particular, exposure to different fields and the timing of the exposure during the undergraduate experience were prominent throughout the data. Although medical schools across Canada share a degree of similarity in their curricula, the clinical experiences and the timing of these differ substantially. It was evident throughout the focus groups that students felt that lack of exposure to specific specialties influenced their decisions. Knowledge of this upon entering medical school may be important for medical students when scheduling extracurricular physician shadowing and clerkship electives. These findings suggest that perhaps medical school curricula should change to favour broader clinical exposure before submitting CaRMS applications. In addition, because there is national coordination and planning for the appropriate mix of physician specialties ${ }^{11}$ to meet changing health care needs and our social accountability mandate, it may be beneficial for the curriculum to allot more time to family medicine to give students the opportunity to experience family medicine from different perspectives and in different contexts. ${ }^{10}$

Although context was determined to be an intermediate theme, it is difficult to assess just how influential it is in decisions about career choice, particularly when linked with limited exposure. With limited exposure to a particular specialty, a single highly positive or highly negative experience (i.e., one that is likely out of context of the norm) may have more of an impact than our analysis would lead us to believe. Because medical students do not have the time to experience each specialty for extended periods, the context of any given clinical experience can be paramount.

Context also extends beyond what was explicitly discussed by the focus group participants. Closely linked to context, as well as modelling and the undergraduate curriculum/experience, is the issue of the hidden curriculum. The hidden curriculum is "lessons that are learned but not openly intended"29 often through cultural norms, values, and expectations. Hafferty and Franks ${ }^{28}$ argue that much of the determinants of who a physician is and how they practice are determined by the hidden curriculum, as opposed to the formal curriculum. Failing to include particular specialties in core rotations or material related to a particular specialty on examinations (Table 1, representative quotation for the undergraduate experience) conveys the message that those specialties are of less value. There is substantial research into the hidden curriculum in medical teaching and practice related to ethics, ${ }^{28,30,31}$ but less research exploring the impact of the hidden curriculum on career choice. In a report released by The Association of Faculties of Medicine of Canada, they consider the impact of the hidden curriculum on career choice and subsequent workforce composition:

The hidden curriculum often supports hierarchies of clinical domains or gives one group advantages over another. It sometimes reinforces the negative elements of existing reward and recognition systems and deters students from pursuing certain careers in medicine, such as family medicine. For these reasons, revealing and clarifying the hidden curriculum will be a challenging yet critical move forward for Canada's Faculties of Medicine. ${ }^{32}$

Regardless of how medical school and residency programs use this information, having a better understanding of these factors can encourage more informed decision-making about career choices. With some medical students still feeling uncertain about their career path after the residency match, more informed decision-making could alleviate some of this uncertainty; understanding that career choice decisions can be flexible even after residency match may also alleviate stress that their decision is not irreversible.

Studies have examined influencing factors toward a particular specialty, such as surgery ${ }^{33}$ or family medicine. ${ }^{25}$ Others have assessed the demographics of medical students selecting a particular specialty, such as emergency medicine and surgery, in an attempt to ascertain a character profile for each specialty. ${ }^{13,15,33}$ Much of the previous research on career choices of medical students has been conducted through surveys. ${ }^{12,33}$ Although some studies have explored the attitudes of Canadian medical students, ${ }^{34}$ most studies on career choice have been outside Canada. ${ }^{12}$

Previous research into career choice has highlighted the importance of work-life balance in the decision-making process. Since Schwartz and colleagues ${ }^{35}$ grouped specialties based on work hours - what they called "controllable lifestyle" — other researchers have investigated the importance of lifestyle factors on career choice., ${ }^{2,83}$ Many of these studies demonstrated that medical students do put an emphasis on expected work-life balance. ${ }^{15}$ Our analysis found that lifestyle was an intermediate influence.

\section{Limitations}

The career choices focus group data used for analysis are from students in the classes of 2003-2008 at a single Canadian medical school. However, student engagement with this project was substantial. The students were interviewed at the end of their training, which yielded retrospective data based on their final career choices and may be affected by recall bias. Further, because we didn't follow up on students' level of satisfaction with their career choice after they entered residency, we are not able to offer commentary on whether students made the "right" career choice. 
Other studies document gender differences in decisionmaking related to lifestyle and life balance..$^{35,36}$ Now that enrolment in Canadian faculties of medicine has a greater proportion of women, the impact of career choice, gender and work-life balance may become increasingly relevant, especially with respect to how gender shapes career trajectories. ${ }^{37}$ We did not specifically analyze the focus group discussions based on gender in the de-identified transcripts.

\section{Conclusion}

Our findings demonstrated that personal philosophy, exposure to specialties and the timing of this exposure are major influencing factors toward career choice. Medical schools can use the knowledge from this study to tailor undergraduate curricula (explicit, hidden and null); students can use this knowledge to reflect on their decision-making, particularly because uncertainty was a minor theme in this study even at the end of undergraduate training. Some students enter medical school having already decided on a specialty, whereas others enter without predilections, and it is likely that their level of self-reflection, certainty and possibly career satisfaction would differ. Future research to examine students' level of self-assessment and self-reflection in their decision-making processes and level of certainty about their selected specialty would be revealing. Focus groups with postgraduate trainees and physicians in early to mid-career could also provide insight into how uncertainty and personal philosophy change through time.p

\section{References}

1. Laurence C, Elliott T. When, what and how South Australian pre-registration junior medical officers' career choices are made. Med Educ 2007;41:467-75.

2. Barshes NR, Vavra AK, Miller A, et al. General surgery as a career: a contemporary review of factors central to medical student specialty choice. 7 Am Coll Surg 2004;199:792-9.

3. Dorsey ER, Jarjoura D, Rutecki GW. The influence of controllable lifestyle and sex on the specialty choices of graduating US medical students, 1996-2003. Acad Med 2005;80:791-6.

4. Leduc N, Vanasse A, Scott I, et al. The career decision-making process of medical students and residents and the choice of specialty and practice location: How does postgraduate medical education fit in? Members of the FMEC PG consortium; 2011.

5. The future of medical education in Canada: a collective vision for MD education, postgraduate project. Ottawa (ON): The Association of Faculties of Medicine of Canada; 2012.

6. Bethune C, Hansen PA, Deacon D, et al. Family medicine as a career option: how students' attitudes changed during medical school. Can Fam Physician 2007;53:881-5, 880.

7. Zinn WM, Sullivan AM, Zotov N, et al. The effect of medical education on primary care orientation: results of two national surveys of students' and residents' perspectives. Acad Med 2001;76:355-65.

8. Table IX - History of family medicine as the career choice of Canadian graduates. Ottawa (ON): Canadian Resident Matching Service; 2014. Available: www.carms.ca/ wp-content/uploads/2014/09/9-History-of-Family-Medicine-as-the-Career-Choice-of -Canadian-Graduates1.pdf (accessed 2015 Jan. 13).

9. 2012 CaRMS R-1 Main residency match results. Mississauga: College of Family Physicians of Canada; 2012. Available: www.cfpc.ca/ProjectAssets/Templates/ NewsItem.aspx?id=4513 (accessed 2015 Jan. 13).

10. Fréchette D, Hollenberg D, Shrichand A, et al. What's really behind Canada's unemployed specialists: Findings from the Royal College's employment study 2013. Ottawa (ON): The Royal College of Physicians and Surgeons of Canada; 2013. Available: www.royalcollege.ca/portal/page/portal/rc/common/documents/ policy/employment report 2013 e.pdf (accessed 2015 July 23).

11. Canadian medical education statistics 2014. Ottawa (ON): The Association of Faculties of Medicine of Canada; 2014. Available: www.afmc.ca/pdf/Cmes2014 -Enrolment.pdf (accessed 2015 July 29).

12. Takeda Y, Morio K, Snell L, et al. Characteristic profiles among students and junior doctors with specific career preferences. BMC Med Educ 2013;13:125.
13. Scott IM, Abu-Laban RB, Gowans MC, et al. Emergency medicine as a career choice: a descriptive study of Canadian medical students. CFEM 2009;11:196-206.

14. Petrides KV, McManus IC. Mapping medical careers: questionnaire assessment of career preferences in medical school applicants and final-year students. BMC Med Educ 2004;4:18.

15. Scott IM, Matejcek AN, Gowans MC, et al. Choosing a career in surgery: factors that influence Canadian medical students' interest in pursuing a surgical career. Can 7 Surg 2008;51:371-7.

16. Weissman C, Tandeter H, Zisk-Rony R, et al. Israeli medical students' perceptions of six key medical specialties. Isr 7 Health Policy Res 2013;2:19.

17. Kassebaum DG, Szenas PL. Relationship between indebtedness and the specialty choices of graduating medical students. Acad Med 1992;67:700-7.

18. Kibbe MR, Troppmann C, Barnett CC, et al. Effect of educational debt on career and quality of life among academic surgeons. Ann Surg 2009;249:342-8.

19. DeZee KJ, Maurer D, Colt R, et al. Effect of financial remuneration on specialty choice of fourth-year US medical students. Acad Med 2011;86:187-93.

20. Vanasse A, Orzanco MG, Courteau J, et al. Attractiveness of family medicine for medical students: influence of research and debt. Can Fam Physician 2011;57: e216-27.

21. Grayson MS, Newton DA, Thompson LF. Payback time: the associations of debt and income with medical student career choice. Med Educ 2012;46:983-91.

22. Newton DA, Grayson MS, Thompson LF. The variable influence of lifestyle and income on medical students' career specialty choices: data from two US medica schools, 1998-2004. Acad Med 2005;80:809-14.

23. Greysen SR, Chen C, Mullan F. A history of medical student debt: observation and implications for the future of medical education. Acad Med 2011;86:840-5.

24. Wright S, Wong A, Newill C. The impact of role models on medical students 7 Gen Intern Med 1997;12:53-6.

25. Parker JE, Hudson B, Wilkinson TJ. Influences on final year medical students attitudes to general practice as a career. 7 Prim Health Care 2014;6:56-63.

26. Brown JB. The use of focus groups in clinical research. In: Crabtree BF, Miller WL, editors. Doing qualitative research. Thousand Oaks (CA): Sage Publications; 1999:109-24.

27. Patton MQ. Qualitative research and evaluation methods. 3rd ed. Thousand Oaks (CA): Sage Publications; 2002.

28. Hafferty FW, Franks R. The hidden curriculum, ethics teaching, and the structure of medical education. Acad Med 1994;69:861-71.

29. Martin J. What should we do with a hidden curriculum when we find one? In: Giroux $\mathrm{H}$, Purpel D, editors. The hidden curriculum and moral education. Berkeley (CA): McCutchan Publishing Corporation; 1983:122-39.

30. Hafferty FW. Beyond curriculum reform: confronting medicine's hidden curriculum. Acad Med 1998;73:403-7.

31. Hafferty FW, Gaufberg EH, O'Donnell JF. The role of the hidden curriculum in "on doctoring" courses. AMA 7 Ethics 2015;17:130-9.

32. The future of medical education in Canada (FMEC): a collective vision for MD education. Ottawa: The Association of Faculties of Medicine of Canada; 2010.

33. Sanfey HA, Saalwachter-Schulman AR, Nyhof-Young JM, et al. Influences on medical student career choice: Gender or generation? Arch Surg 2006;141:1086-94, discussion 1094

34. Scott I, Gowans M, Wright B, et al. Stability of medical student career interest: a prospective study. Acad Med 2012;87:1260-7.

35. Schwartz RW, Haley JV, Williams C, et al. The controllable lifestyle factor and students' attitudes about specialty selection. Acad Med 1990;65:207-10.

36. Alers M, van Leerdam L, Dielissen P, et al. Gendered specialities during medical education: a literature review. Perspect Med Educ 2014;3:163-78.

37. Moulton CA, Seemann N, Webster F. It's all about gender, or is it? Med Educ 2013;47:538-40.

Affiliations: Bachelor of Medicine Class of 2016 (Pianosi), Dalhousie University, Halifax, NS; Discipline of Family Medicine (Bethune), Memorial University, St. John's, NL; Department of Emergency Medicine (Hurley), Dalhousie University, Halifax, NS

Contributors: Katrina Hurley and Cheri Bethune conceived and designed the study. Kiersten Pianosi and Katrina Hurley analyzed the data. Kiersten Pianosi, Katrina Hurley and Cheri Bethune interpreted the data. Each author contributed substantively to the written manuscript and participated in manuscript revisions. All of the authors gave final approval of the version to be published and agreed to act as guarantors of the work.

Acknowledgements: The authors acknowledge the Career Choices research team at Memorial University in St. John's, NL, who helped conceive this project and collected the data. This data analysis was supported by a $\$ 2500$ grant from the IWK Emergency Department Research Fund.

Supplemental information: For reviewer comments and the original submission of this manuscript, please see www.cmajopen.ca/content/4/2/ E147/suppl/DC1. 